\title{
Curious Minds; Serious Play
}

\author{
Jan de Lange
}

Young children are great researchers. The natural amazement and curiosity of young children are the starting points for exploration of their world. Especially for parents with children aged 3-6 years the opportunity should not be missed.

The signals are clear and all point in the same direction: young children (36 years) can do much more than we think. As parents we just have to facilitate the development the talents. There are especially great opportunities to take the natural curiosity of children as a starting point for making talents visible such as logical reasoning and problem solving in a fun and challenging way.

Much research has been done under the name Curious Minds during the period starting in 2005. It's goal was to make visible the talents and insights of young children. The plan behind the Young Parent Academy is to use the results of this research: have parents look in a different way to the early development of their children and support parents with small suggestions in a practical way in order to offer children more challenges when they are playing. The Curious Child, Existing.

J. de Lange $(\triangle)$

Freudenthal Institute, Utrecht, The Netherlands

e-mail: j.delange@uu.nl 


\section{Literature and Our Challenge}

Challenge: how do we get the two cars equally large at the photo? Core Mathematical Concept: Perspective

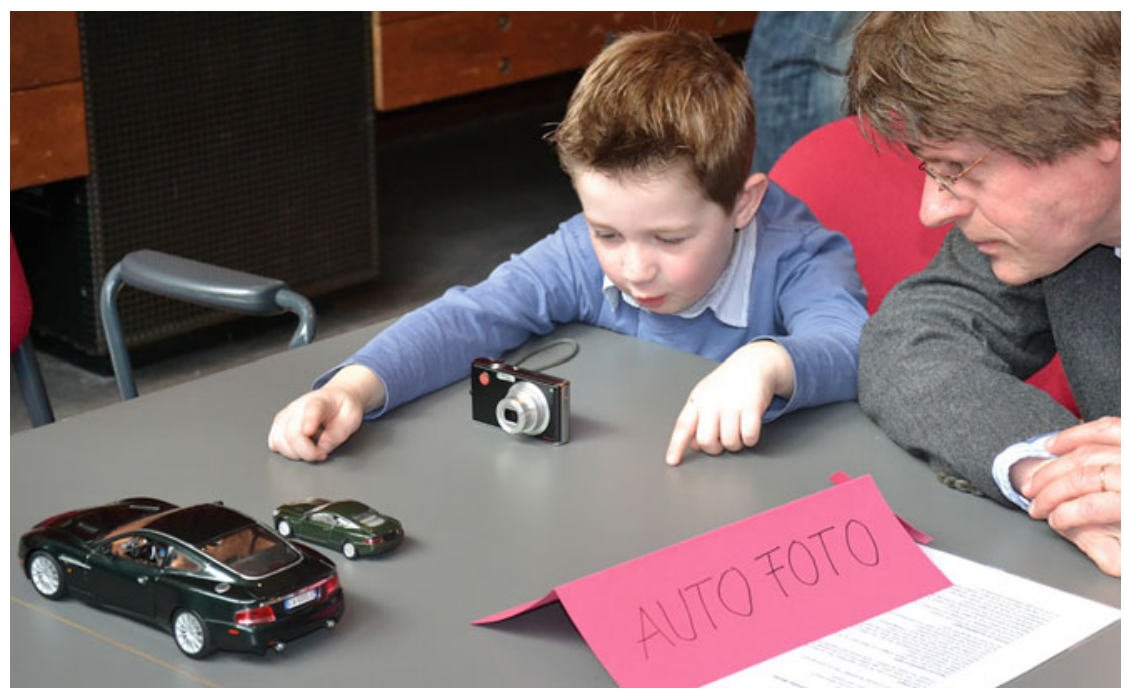

Can we keep the curiosity in the child? Can we further facilitate the development of these very valuable process skills?

If we go back to the start of the Curious minds project the original questions were:

1. What talents, possibilities, and qualities do children in the age-range 3 ton 6 have?

2. How can we optimally enhance the development of these qualities and talents?

3. How intertwined are these talents? Can they be attributed to disciplines as mathematics, science, technology and engineering, or are the more broad and connected?

4. How can scientific talent development be used for language development.

\section{Seven Arguments (If You Need Them) to Get Started}

The arguments to exploit these opportunities are manifold (apologies for deleting the sources).

1. Young children are natural scientists and researchers.

2. Young children can do much more in arithmetic than we think. 
3. Investing in young children is necessary and promising.

4. Investing in young children provides a high return on investment.

5. Young brains give great opportunities to learn and develop.

6. The natural curiosity of young children is the basis for logical thinking.

7. (Serious) play is a way in which children learn. Curiosity, imagination and creativity are like muscles: if you don't use them, you lose them.

\section{Therefore}

\section{DESIGN ACTIVITIES}

We have designed many interesting play-activities with a solid scientific content that have led to new insights how young children reason and think.

The experiments have resulted in the development of more than a hundred activities and are recorded on more than 2000 interviews with 'playing' children.

Connections between formal and informal learning, and between play, reasoning and core scientific concepts are at the core.

Three of these activities were part of the workshop: how to 'classify' (play) animals?, can you copy a Lego building, using Duplo, and make a picture where two similar cars seem to have the same size.

The people attending actually did an excellent job, behaving as young kids. It was a challenge for them as well.

Open Access Except where otherwise noted, this chapter is licensed under a Creative Commons Attribution 4.0 International License. To view a copy of this license, visit http://creativecommons. org/licenses/by/4.0/.

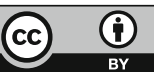

